\title{
Contribution of modifiable risk factors to social inequalities in type 2 diabetes: prospective Whitehall II cohort study
}

\author{
(c) (1) (8) OPEN ACCESS
}

\begin{abstract}
Silvia Stringhini research fellow ${ }^{1}$, Adam G Tabak clinical research associate ${ }^{23}$, Tasnime N Akbaraly senior research fellow ${ }^{245}$, Séverine Sabia research associate ${ }^{2}$, Martin J Shipley senior lecturer ${ }^{2}$, Michael G Marmot professor of epidemiology and director ${ }^{2}$, Eric J Brunner reader ${ }^{2}$, G David Batty Wellcome Trust fellow ${ }^{26}$, Pascal Bovet professor of epidemiology and public health ${ }^{1}$, Mika Kivimäki professor of social epidemiology ${ }^{2}$
\end{abstract}

${ }^{1}$ Institute of Social and Preventive Medicine, Lausanne University Hospital, 1010 Lausanne, Switzerland; ${ }^{2}$ University College London, Department of Epidemiology and Public Health, London, UK; ${ }^{3}$ Semmelweis University, Faculty of Medicine, 1st Department of Medicine, Budapest, Hungary; ${ }^{4}$ Inserm U1061, Montpellier, France; ${ }^{5}$ Université Montpellier I, Montpellier, France; ${ }^{6} \mathrm{MRC}$ Centre for Cognitive Ageing and Cognitive Epidemiology, University of Edinburgh, Edinburgh, UK

\begin{abstract}
Objective To assess the contribution of modifiable risk factors to social inequalities in the incidence of type 2 diabetes when these factors are measured at study baseline or repeatedly over follow-up and when long term exposure is accounted for.

Design Prospective cohort study with risk factors (health behaviours (smoking, alcohol consumption, diet, and physical activity), body mass index, and biological risk markers (systolic blood pressure, triglycerides and high density lipoprotein cholesterol)) measured four times and diabetes status assessed seven times between 1991-93 and 2007-09.

Setting Civil service departments in London (Whitehall II study).

Participants 7237 adults without diabetes (mean age 49.4 years; 2196 women).

Main outcome measures Incidence of type 2 diabetes and contribution of risk factors to its association with socioeconomic status.

Results Over a mean follow-up of 14.2 years, 818 incident cases of diabetes were identified. Participants in the lowest occupational category had a 1.86 -fold (hazard ratio $1.86,95 \%$ confidence interval 1.48 to 2.32 ) greater risk of developing diabetes relative to those in the highest occupational category. Health behaviours and body mass index explained $33 \%(-1 \%$ to $78 \%)$ of this socioeconomic differential when risk factors were assessed at study baseline (attenuation of hazard ratio from 1.86 to 1.51$), 36 \%$ (22\% to $66 \%$ ) when they were assessed repeatedly over the follow-up (attenuated hazard ratio 1.48 ), and $45 \%$ (28\% to $75 \%$ ) when long term exposure over the follow-up was accounted for (attenuated hazard ratio 1.41). With additional adjustment for biological
\end{abstract}

risk markers, a total of $53 \%$ (29\% to $88 \%$ ) of the socioeconomic differential was explained (attenuated hazard ratio 1.35, 1.05 to 1.72).

Conclusions Modifiable risk factors such as health behaviours and obesity, when measured repeatedly over time, explain almost half of the social inequalities in incidence of type 2 diabetes. This is more than was seen in previous studies based on single measurement of risk factors.

\section{Introduction}

Diabetes is a major cause of morbidity and premature mortality worldwide. ${ }^{12}$ In 2011 the World Health Organization estimated that as many as 346 million people lived with the disease, $90 \%$ of whom had type 2 diabetes. ${ }^{3}$ In addition to its own treatment burden, which exacts enormous healthcare expenditure, ${ }^{4}$ type 2 diabetes is also an established risk factor for cardiovascular diseases, ${ }^{5}$ selected cancers, ${ }^{6}$ and possibly mood disorder and dementia. ${ }^{7}$ Thus, identification of those groups at increased risk of type 2 diabetes, together with an understanding of the mechanisms involved, remains a public health priority. Research has now established that the occurrence of type 2 diabetes is not evenly distributed across society: in high income countries, the lower socioeconomic groups are disproportionately affected. ${ }^{8-12}$ However, much remains to be learnt about the modifiable risk factors that contribute to socioeconomic variations in type 2 diabetes.

Differences in the availability or affordability of healthy foods or places to exercise, differential access to healthcare services 
and health information, and differences in health related behaviours between socioeconomic groups have all been proposed as potential explanations for the social patterning of type 2 diabetes. ${ }^{13}{ }^{14}$ Among these, physical inactivity, obesity, unhealthy diet, and cigarette smoking are established risk factors for the development of the disease and have been shown to be more prevalent among the disadvantaged socioeconomic groups. ${ }^{15-20}$ They are thus potentially important mediators of the association between socioeconomic status and type 2 diabetes. However, previous studies suggest that these factors can explain only about a third of social inequalities in type 2 diabetes. ${ }^{10} 122122$

In a recent study in the British Whitehall II cohort, we showed that health behaviours explain a greater proportion of social inequalities in mortality when they are assessed repeatedly over the follow-up rather than at baseline only. ${ }^{23}$ Most studies on type 2 diabetes offer only a one-off measurement of health behaviours, so previous studies may have underestimated their contribution. In this study, we used data from the Whitehall II cohort to assess the contribution of smoking, alcohol consumption, dietary behaviours, physical activity, and body mass index to social inequalities in the incidence of type 2 diabetes. We compared their role when they were assessed at study baseline or repeatedly over the follow-up and when long term exposure was accounted for. Furthermore, we evaluated the additional contribution of biological risk markers for type 2 diabetes that are commonly measured in clinical settings: systolic blood pressure, triglycerides, and high density lipoprotein cholesterol.

\section{Methods}

\section{Study population and design}

The Whitehall II study was established in 1985 among 10308 (3413 women) London based civil servants aged $35-55$ years. ${ }^{24}$ The first examination (phase 1) took place during 1985-88 and involved a clinical examination and a self administered questionnaire. A $75 \mathrm{~g}$ oral glucose tolerance test was done for the first time at phase $3(1991-93 ; \mathrm{n}=8815)$ and repeated at phase 5 (1997-99), phase 7 (2003-04), and phase 9 (2007-09).

Therefore, the phase 3 examination is the baseline for the analyses we report here. We included participants free of type 2 diabetes at phase 3 and followed them for incident diabetes up to phase 9 . Additional questionnaire only phases also assessed diabetes status at phase 4 (1995-96), phase 6 (2001), and phase 8 (2006).

\section{Socioeconomic status}

Socioeconomic status was based on participants' occupational position at phase 3 and categorised into high (administrative), intermediate (professional/executive), and low (clerical/support). This measure is a comprehensive marker of socioeconomic circumstances and is related to education, salary, social status, and level of responsibility at work. ${ }^{24} 25$

\section{Diabetes risk factors and risk markers}

Health behaviours were assessed at phases 1, 3, 5, and 7. Current smoking was self reported and classified as yes/no. Alcohol consumption was assessed by using questions on the number of alcoholic drinks consumed in the previous week, then converted to number of alcohol units consumed per week and categorised as "abstainers" ( 0 units/week), "moderate drinkers" (1-21/1-14 units/week for men/women), or "heavy drinkers" ( $\geq 21 / \geq 14$ units/week for men/women). ${ }^{26}$
Overall diet was assessed by calculating a score of adherence to healthy dietary guidelines provided by the alternative healthy eating index. ${ }^{27} 28$ This index was based on intake levels of vegetables, fruit, nuts, and soy, white to red meat ratio, total fibre, trans fat, polyunsaturated to saturated fatty acids ratio, long term multivitamin use, and alcohol consumption. ${ }^{28}$ The score was then trichotomised on the basis of tertiles. As the alternative healthy eating index was not available for phase 1 , a diet score was calculated by using information on fruit and vegetable intake and the type of bread and milk most commonly consumed, as described previously. ${ }^{23}$

Physical activity was assessed by using questions on the frequency and duration of participation in moderate or vigorous physical activity at phases 1 and 3 . At phases 5 and 7, the questionnaire included 20 items on frequency and duration of participation in different physical activities that were used to calculate hours per week at each intensity level. ${ }^{29}$ Participants were classified as "active" $(\geq 2.5$ hours/week of moderate or $\geq 1$ hour/week of vigorous physical activity), "inactive" $(\leq 1$ hour/week of moderate and $\leq 1$ hour/week of vigorous physical activity), or "moderately active" (if not active or inactive).

Height and weight were measured at phases 1, 3, 5, and 7 by following standard procedures. Body mass index was then calculated and categorised in three groups (normal, $<25$; overweight, 25-29; obese, $\geq 30$ ) on the basis of WHO recommendation. ${ }^{30}$

Biological risk markers related to type 2 diabetes were drawn from phases $1,3,5$, and 7 and categorised into high and low risk groups. ${ }^{31}{ }^{32}$ High triglycerides were defined as $\geq 1.7 \mathrm{mmol} / \mathrm{L}$ and low high density lipoprotein cholesterol as $<1.0 \mathrm{mmol} / \mathrm{L}$ in men and $<1.2 \mathrm{mmol} / \mathrm{L}$ in women. High systolic blood pressure was defined as $\geq 140 \mathrm{~mm} \mathrm{Hg}$. At phase 1 , high density lipoprotein cholesterol measurements were available for only 1208 participants and triglycerides for only 1758 . We predicted missing high density lipoprotein cholesterol data by using data on apolipoprotein A I, as described previously. ${ }^{33}$ Cumulative exposure to high triglycerides concentrations between phases 1 and 3 could not be assessed.

Ethnicity was drawn from phase 1 and categorised as white/non-white. Family history of type 2 diabetes (parents and siblings) was self reported at phases 1 and 2 and categorised as yes/no.

\section{Incident type 2 diabetes}

Venous blood was taken after a requested minimum five hour fast before participants had a standard $75 \mathrm{~g}$ two hour oral glucose tolerance test at study phases 3,5,7, and 9. Glucose samples were drawn into fluoride monovette tubes and centrifuged on site within one hour. Blood glucose was measured by using the glucose oxidase method, as previously described. ${ }^{34}$ At each phase, diabetes was defined by WHO criteria based on fasting glucose $\geq 7.0 \mathrm{mmol} / \mathrm{L}$ or two hour glucose $\geq 11.1 \mathrm{mmol} / \mathrm{L}$. ${ }^{35}$ Participants reporting diabetes diagnosed by a doctor or use of antidiabetic drugs were classified as having diabetes regardless of their oral glucose tolerance test results. The date of diagnosis of diabetes was assigned according to the interval method as the midpoint between the first visit with a diagnosis of diabetes and the last visit without diabetes. ${ }^{34}$

\section{Statistical analysis}

We applied multivariate imputation based on sex, age, ethnicity, socioeconomic status, health behaviours, body mass index, and biological markers at the preceding phase to impute missing values on health behaviours, body mass index, or biological 
risk markers at phases 3,5 , and 7 . Twenty per cent of the participants had at least one value imputed at one of the follow-ups.

As no differences related to sex or ethnicity were apparent in the association between socioeconomic status and incidence of type 2 diabetes (hazard ratio 1.85, 95\% confidence interval 1.45 to 2.45 , among men and $1.71,1.16$ to 2.43 , among women, $\mathrm{P}$ for interaction $=0.80 ; 1.89,1.49$ to 2.41 , among white people and $1.59,0.85$ to 2.95 , among non-white people, $\mathrm{P}$ for interaction $=0.98$ ), we pooled data for the two sexes and the two ethnic groups and adjusted analyses for sex and ethnicity. We used Cox regression to examine the association of socioeconomic status, health behaviours, body mass index, and biological risk markers with incident diabetes. As tests did not suggest departure from a linear trend ( $\mathrm{P}$ for departure from a linear trend $=0.20$ ), we used socioeconomic status as a continuous three level variable. Sensitivity analysis using socioeconomic status as a categorical variable yielded similar results (supplementary table G). We squared the hazard ratio associated with a unit change in socioeconomic status to yield the hazard ratio for lowest versus highest category of socioeconomic status.

We firstly adjusted Cox regression models for age, sex, ethnicity, and family history of diabetes (model 1 or reference model 1). We then entered health behaviours and body mass index first individually and then simultaneously into model 1. Model 2 included adjustment for all health behaviours, and model 3 (or reference model 2 for further model comparisons) included adjustment for all health behaviours and body mass index. Subsequently, we entered the biological markers individually into model 3, and we finally entered all risk factors/markers simultaneously into a full multivariable model (model 4).

We determined the contribution of each risk factor/marker in explaining the association between socioeconomic status and type 2 diabetes by calculating the percentage attenuation in the $\beta$ coefficient for socioeconomic status after inclusion of the risk factor in question in the reference model: " $100 \times\left(\beta_{\text {ref model }}-\beta_{\text {ref }}\right.$ $(\mathrm{s}) /\left(\beta_{\text {ref model }}\right)$ ". We calculated a $95 \%$ confidence interval around the percentage attenuation by using a bootstrap method with 1000 re-samplings. We repeated the analyses for the role of risk factors/markers in the association between socioeconomic status and type 2 diabetes three times using different assessments. Firstly, we entered risk factors/markers as assessed at the baseline of the study (phase 3). Secondly, we assessed them longitudinally over the follow-up (phases 3, 5, and 7) and entered them in the Cox regressions as time dependent variables. Thirdly, we extended this model to assess long term exposure to the risk factors/markers. We assessed this by adjusting, at each follow-up period, for the risk factors/markers at the current phase plus at the previous phase (two phases capturing an exposure period of approximately five years). Thus, for the follow-up period between phases 3 and 5, we entered risk factors/markers assessed at phase 3 into the model together with the risk factors/markers assessed at phase 1. For the follow-up period between phases 5 and 7, were entered risk factors/markers collected at phases 3 and 5 simultaneously, and for the follow-up period between phases 7 and 9, we entered risk factors/markers from phases 5 and 7 together. We tested the proportional hazard assumptions for Cox regression models by using Schoenfeld residuals and found them not to be violated (all P values $\geq 0.05$ ). We used the statistical software Stata 11.1 and SAS 9.2 (\%BOOT and \%BOOTCI macros) for analyses.

\section{Results}

Of the 8815 participants who took part in the phase 3 examination (that is, the baseline of the analyses reported here), we excluded 1578 for one or more of the following reasons: prevalent type 2 diabetes at phase $3(n=162)$, missing follow-up on type 2 diabetes status $(\mathrm{n}=588)$, and missing data on risk factors/markers at phase $1(\mathrm{n}=1392)$. The final sample consisted of 7237 participants (2196 women). Excluded participants were more likely to belong to the low socioeconomic status group and were slightly older than those included in the analyses $(\mathrm{P}<0.001)$.

Table $1 \Downarrow$ shows baseline characteristics of the participants included in the analysis. During the mean 14.2 years follow-up, 818 incident cases type 2 diabetes were identified on the basis of a $75 \mathrm{~g}$ oral glucose tolerance test $(\mathrm{n}=425 ; 52 \%)$, use of antidiabetic drugs $(\mathrm{n}=188 ; 23 \%)$, or diagnosis by a physician $(n=205 ; 25 \%)$. Participants in the lowest socioeconomic category had an almost twofold higher incidence of type 2 diabetes than those in the highest category ( $10.9 v 5.6$ per 1000 person years). The prevalences of smoking, unhealthy diet, physical inactivity, obesity, high triglyceride concentration, and low high density lipoprotein cholesterol were higher in the lowest compared with the highest socioeconomic group $(\mathrm{P}<0.001)$, whereas heavy drinking was more common in the highest socioeconomic group $(\mathrm{P}<0.001)$. Socioeconomic status was unrelated to high blood pressure $(\mathrm{P}=0.72)$.

Table $2 \Downarrow$ shows results for the association between risk factors/markers for diabetes and incidence of type 2 diabetes. Unhealthy behaviours were related to an increased risk of developing type 2 diabetes over the follow-up. As anticipated, the associations of overweight (hazard ratio $1.92,95 \%$ confidence interval 1.64 to 2.25 ) and obesity $(4.79,3.96$ to 5.80$)$ with incidence of type 2 diabetes were particularly strong. Hypertension and adverse lipid categories were also associated with type 2 diabetes, as was family history of diabetes.

Table $3 \Downarrow$ shows results for the association between socioeconomic status and incidence of type 2 diabetes, as well as the contribution of health behaviours, body mass index, and biological risk markers assessed at phase 3 to this association. The hazard ratio for the lowest versus the highest socioeconomic status was 1.86 (1.48 to 2.32 ). This was attenuated by $17 \%$ when we controlled for health behaviours at baseline and by $18 \%$ when we controlled for body mass index. Overall, health behaviours and body mass index attenuated the association between socioeconomic status and type 2 diabetes by $33 \%$ ( $-1 \%$ to $78 \%$ ). Adjustment for baseline biological risk markers (entered as continuous variables in the model) lowered the association by an additional $12 \%$. In total, $45 \%$ (17\% to $105 \%$ ) of the socioeconomic gradient in type 2 diabetes was explained. In table $4 \Downarrow$ shows the results when the risk factors/markers were assessed repeatedly over the follow-up. The first column shows that with longitudinal assessment over the follow-up, health behaviours and body mass index in combination explained $36 \%$ ( $22 \%$ to $64 \%$ ) of the association between socioeconomic status and type 2 diabetes. This proportion increased to $45 \%$ (28\% to $77 \%$ ) when we additionally took blood lipids and systolic blood pressure into account. The right side of table $4 \Downarrow$ shows results of simultaneous adjustment for long term exposure to the risk factors/markers and their changes over time. In this model, health behaviours attenuated the socioeconomic status coefficient by $24 \%$ and body mass index alone by $23 \%$; the total percentage attenuation due to health behaviours and body mass index was $45 \%$ (28\% to $75 \%$ ). Blood lipids and blood pressure contributed to an additional $8 \%$, and in the final fully adjusted 
model $53 \%$ (29\% to $88 \%$ ) of the association between socioeconomic status and type 2 diabetes was explained.

\section{Sensitivity analyses}

We repeated all analyses in subgroups including only participants with complete data, only those who were free from coronary heart disease at baseline, and only white participants, as well as including adjustment for waist circumference and body mass index assessed at age 25 . These yielded similar results to those reported in the main analysis (results available on request).

We repeated all analyses for men and women separately (supplementary tables A to D). Although results did not materially differ between the sexes, modifiable risk factors tended to explain a larger proportion of the socioeconomic gradient in type 2 diabetes in women than in men (attenuation for the model accounting for long term exposure to the risk factors: $42 \%$ in men and $81 \%$ in women, $P$ for difference between the two estimations $=0.43$ ).

To examine whether our results are robust across different indicators of socioeconomic status, we repeated all analyses using education and income as alternative measures. Our findings of a major contribution of modifiable risk factors to socioeconomic differences in type 2 diabetes were consistent across the indicators of socioeconomic status (supplementary tables $\mathrm{E}$ and $\mathrm{F}$ ). We also repeated the analysis using employment grade in six categories (supplementary table G). Again, the results were very similar to those in the main analysis based on employment grade in three categories.

Finally, we used three standard approaches to examine whether missing data on risk factors at baseline affected the findings. Firstly, we repeated the analysis using only three of the risk factors examined: smoking, alcohol consumption, and body mass index. These risk factors were available on a larger sample of the population $(\mathrm{n}=7750)$, allowing us to assess whether their role in explaining socioeconomic differences in type 2 diabetes in this larger sample was similar to that found in the smaller sample included in the main analysis. Regarding the model with baseline assessment of these risk factors, the contribution of smoking was $10 \%$ in the larger sample compared with $9 \%$ in the smaller sample. The contribution of alcohol consumption was $3 \%$ versus $3 \%$, and that of body mass index was $20 \%$ versus $18 \%$. Secondly, we used "inverse probability weighting" to correct the estimates for non-response. ${ }^{36}$ These analyses yielded similar results to those reported in the main analysis (supplementary table H). Thirdly, we used multiple multivariate imputation to replace missing values for risk factors at the study baseline (Stata ice/micombine procedures). Analyses on the imputed dataset ( $\mathrm{n}=8232 ; 927$ incident diabetes cases) yielded results virtually identical to those reported in the main analysis (results available on request).

\section{Discussion}

This study aimed to quantify the contribution of health behaviours, body mass index, and biological risk markers to the association between socioeconomic status and the incidence of type 2 diabetes in a population of British civil servants followed up for a mean of 14.2 years. We found that health behaviours and body mass index explained $33 \%$ of socioeconomic differences in incidence of diabetes when they were assessed at study baseline, $36 \%$ when assessed repeatedly over the follow-up, and $45 \%$ when we additionally accounted for long term exposure. In these three assessments, body mass index was the most important single contributing factor. After we additionally took account of adverse lipid profile and systolic blood pressure, up to $53 \%$ of the association between socioeconomic status and type 2 diabetes was explained.

\section{Strengths and weaknesses}

This study has two major strengths. Firstly, it is to our knowledge the first to assess the effect of health behaviours and body mass index on socioeconomic differences in type 2 diabetes by using different assessments of current and long term exposure to these factors over the follow-up. This allowed us to examine the possibility that changes in these factors over the study period or a long term exposure might have yielded different results. Secondly, unlike previous studies, we provide a confidence interval around the percentage attenuation of the association between socioeconomic status and type 2 diabetes after inclusion of the risk factors examined. Adding a degree of precision to the estimates of the contribution of risk factors to social inequalities greatly helps with the interpretation of these findings.

This study also has some limitations. As the findings were from an occupational cohort, they may not fully apply to the general population, which also includes people not in paid employment. Despite a high response to the survey at the successive data collection phases, loss to follow-up accumulated over the extended time period, as is inevitable in long term prospective studies. We used an imputation procedure to replace missing values for the risk factors considered. Our sensitivity analyses showed that results from analyses using complete case data differed little from those using imputed data.

\section{Comparison with previous studies}

In our study, participants in the lowest occupational group had a 1.86-fold greater risk of developing type 2 diabetes over the follow-up compared with those in the highest occupational group. This is slightly higher than the 1.31 -fold increased risk of incident type 2 diabetes in the lowest category of socioeconomic status found in the most recent meta-analysis of cohort studies in high income countries. ${ }^{11}$ Health behaviours and body mass index explained about a third of socioeconomic differences in incidence of type 2 diabetes when assessed at baseline - this is consistent with previous reports on this and other cohorts ${ }^{1021} 22$-but up to $45 \%$ when we accounted simultaneously for changes over time and long term exposure. The difference in contributions of risk factors when measured once compared with repeatedly was mainly due to an increased explanatory power of physical activity (from $1 \%$ to $10 \%$ ) and body mass index (from $18 \%$ to $23 \%$ ). Long term exposure to these risk factors may be captured better when it is assessed at multiple points in time rather than on just one occasion.

Moreover, adjustment for the long term effect of body mass index may be important, as duration of exposure to obesity has been linked to increased risk of type 2 diabetes. ${ }^{37}$

Recent studies have suggested that social inequalities in type 2 diabetes might be larger in women than in men, ${ }^{38}{ }^{39}$ whereas in our study the socioeconomic gradient in incidence of type 2 diabetes did not differ by sex. Our data came from an occupational cohort, which may result in the characteristics for men and women being more homogeneous than in the general population. Moreover, most studies reporting sex differences in the social patterning of type 2 diabetes were based on prevalence data, ${ }^{38} 39$ whereas our study examined incidence. However, in our study the modifiable risk factors examined tended to explain a larger proportion of the association between socioeconomic status and type 2 diabetes in women than in men, 
because of sex differences in the social patterning of these risk factors.

In contrast to our previously published paper on socioeconomic differences in mortality, ${ }^{23}$ the contribution of health behaviours to social inequalities in incidence of type 2 diabetes did not increase substantially when we used repeated assessments of the behaviours during the follow-up rather than using only one assessment at baseline. The effect of changes in unhealthy behaviours may be more pronounced on determinants of mortality than for type 2 diabetes. Alternatively, reverse causation could partly explain the larger proportion of socioeconomic differences explained with repeated versus baseline only assessment when the outcome is mortality instead of morbidity. ${ }^{40}$ In mortality analyses, changes in unhealthy behaviours may be elicited by non-fatal chronic diseases preceding death.

\section{Meaning and implications of study}

Of the modifiable risk factors examined, body mass index contributed the most and alone explained about $20 \%$ of socioeconomic differences. The major role of excess weight in the onset of type 2 diabetes is well established. ${ }^{41}$ As weight gain is strongly socially patterned, the finding that obesity also plays a major role in shaping social inequalities in type 2 diabetes is not surprising. In contrast, with only $8 \%$ and $1 \%$ attenuation of the association between socioeconomic status and type 2 diabetes ( $8 \%$ and $10 \%$ when we assessed long term exposure), the effects of diet and physical activity were smaller than one would expect given that these behaviours were also strongly socially patterned. We might have underestimated their effect relative to that of body mass index because this is measured with greater precision than questionnaire based diet and physical activity assessment. ${ }^{42} 43$

Although smoking was associated with incidence of type 2 diabetes and was strongly socially patterned, its contribution to socioeconomic differences in type 2 diabetes was modest. The role of alcohol consumption was also negligible. This is probably because participants in the highest category of socioeconomic status were more likely to be heavy drinkers than were those in the lowest category, a finding also observed in other occupational cohorts. ${ }^{44} \mathrm{We}$ found that dyslipidaemia (high triglycerides in particular) explained an additional $10 \%$ of socioeconomic differences in incidence of type 2 diabetes. In contrast, the contribution of hypertension was almost null, consistent with equal distribution of elevated blood pressure across socioeconomic groups and the lack of socioeconomic inequalities in prescription of antihypertensive drugs in the United Kingdom. ${ }^{45}$ The treatment of high triglycerides and low high density lipoprotein cholesterol is not a primary aim in clinical practice; these biomarkers are unlikely to affect the social patterning of diabetes. ${ }^{46}$

The fact that unhealthy behaviours and body mass index explained up to $45 \%$ of the socioeconomic gradient in type 2 diabetes in this population in early old age has important public health implications. Type 2 diabetes can be delayed or prevented among people at high risk who make intensive lifestyle modifications. ${ }^{47}{ }^{48}$ Further efforts should be made to promote and enable the adoption of healthy lifestyles among the disadvantaged fractions of society. Targeting diabetogenic lipid profiles might additionally be considered, ${ }^{49}$ as in our study dyslipidaemia (high triglycerides in particular) explained an additional $10 \%$ of socioeconomic differences in incidence of type 2 diabetes. However, the extent to which altered concentrations of triglycerides are a consequence of increased adiposity or insulin resistance or are an independent risk factor for the development of type 2 diabetes remains unclear. ${ }^{5051}$ Moreover, clinical implications should take into account the fact that drugs that directly target triglycerides and high density lipoprotein cholesterol are associated with a slight increase in blood glucose concentrations, an unwanted side effect for people at high risk of diabetes, ${ }^{52}$ and are less effective than expected. ${ }^{53}$

\section{Unanswered questions}

Similarly to previous findings on cardiovascular diseases in this cohort, ${ }^{54}$ about $50 \%$ of the socioeconomic gradient in type 2 diabetes remained unexplained after we had accounted for all major risk factors for the disease. Other potential mediators of the association between socioeconomic status and type 2 diabetes in adults are psychosocial factors and psychological states, such as chronic stressors and depression, ${ }^{13} 56$ exposure to adverse socioeconomic circumstances in utero or during childhood, ${ }^{57}$ or inadequate access to healthcare. ${ }^{13}$ However, studies that have assessed the contribution of psychosocial factors have found no evidence for an effect on social inequalities in diabetes, ${ }^{1021}$ and medical care seems to contribute more to social inequalities in management of diabetes than to its onset. ${ }^{13}$ Although evidence suggests that exposure to adverse socioeconomic circumstances in early life or depression might play a role in social inequalities in type 2 diabetes, ${ }^{56}{ }^{58}$ to our knowledge no study so far has investigated this question. Further investigations based on longitudinally assessed risk factors are therefore needed. Finally, as noted above, the extent to which unhealthy diet and low physical activity would contribute to the socioeconomic gradient in type 2 diabetes remains unknown until these risk factors are assessed with greater precision at the population level—for example, with objective measures.

\section{Conclusions}

Health behaviours and body mass index explain almost half of the association between socioeconomic status and incidence of type 2 diabetes. Adverse blood lipids, which might be an intervention target for prevention of diabetes in the future, also contributed to social inequalities associated with type 2 diabetes. Given the increasing burden of type 2 diabetes and the observed increase in social inequalities in prevalence of type 2 diabetes, ${ }^{52}$ further efforts to tackle these factors are urgently needed.

We thank all of the participating civil service departments and their welfare, personnel, and establishment officers; the British Occupational Health and Safety Agency; the British Council of Civil Service Unions; all participating civil servants in the Whitehall II study; and all members of the Whitehall II Study Team. The Whitehall II Study Team comprises research scientists, statisticians, study coordinators, nurses, data managers, administrative assistants, and data entry staff, who make the study possible.

Contributors: SStringhini analysed the data and wrote the first and successive drafts of the paper. MK conceived the study. MK, AT, MS, and SSabia contributed to data analysis. All authors contributed to the interpretation of results and to the writing of the paper, critically revised each version of the manuscript, and approved the final version of the paper. S Stringhini is the guarantor.

Funding: SStringhini is supported by a postdoctoral fellowship awarded by the Swiss School of Public Health. MK is supported by the UK Medical Research Council (MRC), the US National Institutes of Health (NIH) (R01HL036310; R01AG034454), the EU New OSH ERA Research Programme, and an Economic and Social Research Council (ESRC) professorship. DB is a Wellcome Trust fellow. TA is supported by the National Heart, Lung, and Blood Institute (R01HL036310). SSabia is 


\section{What is already known on this topic}

The burden of type 2 diabetes disproportionally affects the lower socioeconomic groups, but the reasons for its uneven distribution remain unclear

Lifestyle related risk factors are potentially important mediators of the association between socioeconomic status and type 2 diabetes

Previous studies have offered only a one-off measurement of these factors and have potentially underestimated their effect on social inequalities in incidence of type 2 diabetes

\section{What this study adds}

Health behaviours and body mass index, when assessed repeatedly over time, explained almost half of the association between socioeconomic status and incidence of type 2 diabetes

Adverse blood lipids, which might be an intervention target for prevention of diabetes in the future, also contributed to explaining the social inequalities in incident type 2 diabetes

supported by a grant from the National Institute of Aging, $\mathrm{NIH}$ (R01AG034454). MS is supported by the British Heart Foundation. The Whitehall II study has been supported by grants from the MRC; the British Heart Foundation; the British Health and Safety Executive; the British Department of Health; the National Heart, Lung, and Blood Institute (R01HL036310); and the National Institute on Aging, NIH. The University of Edinburgh Centre for Cognitive Ageing and Cognitive Epidemiology is funded as part of the joint UK research council call for lifelong health and wellbeing. The funding organisations or sponsors had no role in the design and conduct of the study; collection, management, analysis, and interpretation of the data; or preparation, review, or approval of the manuscript.

Competing interests: All authors have completed the ICMJE uniform disclosure form at www.icmje.org/coi_disclosure.pdf (available on request from the corresponding author) and declare: no support from any organisation for the submitted work; no financial relationships with any organisations that might have an interest in the submitted work in the previous three years; no other relationships or activities that could appear to have influenced the submitted work.

Ethical approval: This study was approved by the University College London ethics committee, and all participants provided written consent. Data sharing: Whitehall II data are available to the scientific community. Please refer to the Whitehall II data sharing policy at www.ucl.ac.uk/ whitehalllI/data-sharing.

International Diabetes Federation. The diabetes atlas. Third Edition. IDF, 2006.

2 Danaei G, Lawes CM, Vander Hoorn S, Murray CJ, Ezzati M. Global and regional mortality from ischaemic heart disease and stroke attributable to higher-than-optimum blood glucose concentration: comparative risk assessment. Lancet 2006;368:1651-9.

$3 \quad$ World Health Organization. Diabetes. (Fact sheet No 312.) WHO, 2011.

4 Zhang P, Engelgau MM, Norris SL, Gregg EW, Narayan KM. Application of economic analysis to diabetes and diabetes care. Ann Intern Med 2004;140:972-7.

5 Diabetes mellitus: a major risk factor for cardiovascular disease. A joint editorial statement by the American Diabetes Association; the National Heart, Lung, and Blood Institute; the Juvenile Diabetes Foundation International; the National Institute of Diabetes and Digestive and Kidney Diseases; and the American Heart Association. Circulation 1999;100:1132-3.

6 Coughlin SS, Calle EE, Teras LR, Petrelli J, Thun MJ. Diabetes mellitus as a predictor of cancer mortality in a large cohort of US adults. Am J Epidemiol 2004;159:1160-7.

7 Pan A, Lucas M, Sun Q, van Dam RM, Franco OH, Manson JE, et al. Bidirectional association between depression and type 2 diabetes mellitus in women. Arch Intern Med 2010;170:1884-91.

8 Matsushima M, Shimizu K, Maruyama M, Nishimura R, LaPorte RE, Tajima N. Socioeconomic and behavioural risk factors for mortality of individuals with IDDM in Japan: population-based case-control study. Diabetologia 1996;39:710-6.

9 Maty SC, Everson-Rose SA, Haan MN, Raghunathan TE, Kaplan GA. Education, income, occupation, and the 34-year incidence (1965-99) of type 2 diabetes in the Alameda County Study. Int J Epidemiol 2005;34:1274-81.

10 Kumari M, Head J, Marmot M. Prospective study of social and other risk factors for incidence of type 2 diabetes in the Whitehall II study. Arch Intern Med 2004;164:1873-80.

11 Agardh E, Allebeck P, Hallqvist J, Moradi T, Sidorchuk A. Type 2 diabetes incidence and socio-economic position: a systematic review and meta-analysis. Int $\mathrm{J}$ Epidemiol 2011;40:804-18.

12 Wikstrom K, Lindstrom J, Tuomilehto J, Saaristo TE, Korpi-Hyovalti E, Oksa H, et al. Socio-economic differences in dysglycemia and lifestyle-related risk factors in the Finnish middle-aged population. Eur J Public Health 2011;21:768-74.

13 Brown AF, Ettner SL, Piette J, Weinberger M, Gregg E, Shapiro MF, et al. Socioeconomic position and health among persons with diabetes mellitus: a conceptual framework and review of the literature. Epidemiol Rev 2004;26:63-77.

14 Robbins JM, Vaccarino V, Zhang H, Kasl SV. Socioeconomic status and type 2 diabetes in African American and non-Hispanic white women and men: evidence from the third national health and nutrition examination survey. Am J Public Health 2001;91:76-83.

15 Perry IJ, Wannamethee SG, Walker MK, Thomson AG, Whincup PH, Shaper AG. Prospective study of risk factors for development of non-insulin dependent diabetes in middle aged British men. BMJ 1995;310:560-4.
16 Willi C, Bodenmann P, Ghali WA, Faris PD, Cornuz J. Active smoking and the risk of type 2 diabetes: a systematic review and meta-analysis. JAMA 2007;298:2654-64.

17 Hu G, Lindstrom J, Valle TT, Eriksson JG, Jousilahti P, Silventoinen K, et al. Physical activity, body mass index, and risk of type 2 diabetes in patients with normal or impaired glucose regulation. Arch Intern Med 2004:164:892-6.

18 Chinn DJ, White M, Harland J, Drinkwater C, Raybould S. Barriers to physical activity and socioeconomic position: implications for health promotion. J Epidemiol Community Health 1999;53:191-2.

19 Irala-Estevez JD, Groth M, Johansson L, Oltersdorf U, Prattala R, Martinez-Gonzalez MA. A systematic review of socio-economic differences in food habits in Europe: consumption of fruit and vegetables. Eur J Clin Nutrition 2000:54:706-14

20 Osler M. Social class and health behaviour in Danish adults: a longitudinal study. Public Health 1993;107:251-60.

21 Agardh EE, Ahlbom A, Andersson T, Efendic S, Grill V, Hallqvist J, et al. Explanations of socioeconomic differences in excess risk of type 2 diabetes in Swedish men and women. Diabetes Care 2004;27:716-21.

22 Williams ED, Tapp RJ, Magliano DJ, Shaw JE, Zimmet PZ, Oldenburg BF. Health behaviours, socioeconomic status and diabetes incidence: the Australian Diabetes Obesity and Lifestyle Study (AusDiab). Diabetologia 2010;53:2538-45.

23 Stringhini S, Sabia S, Shipley M, Brunner E, Nabi H, Kivimaki M, et al. Association of socioeconomic position with health behaviors and mortality. JAMA 2010;303:1159-66.

24 Marmot MG, Smith GD, Stansfeld S, Patel C, North F, Head J, et al. Health inequalities among British civil servants: the Whitehall II study. Lancet 1991;337:1387-93.

25 Elovainio M, Ferrie JE, Singh-Manoux A, Shipley M, Batty GD, Head J, et al. Socioeconomic differences in cardiometabolic factors: social causation or health-related selection? Evidence from the Whitehall II cohort study, 1991-2004. Am J Epidemio 2011;174:779-89.

26 Britton A, Singh-Manoux A, Marmot MG. Alcohol consumption and cognitive function in the Whitehall II Study. Am J Epidemiol 2004;160:240-7.

27 McCullough ML, Feskanich D, Stampfer MJ, Giovannucci EL, Rimm EB, Hu FB, et al. Diet quality and major chronic disease risk in men and women: moving toward improved dietary guidance. Am J Clin Nutrition 2002;76:1261-71.

28 Akbaraly TN, Ferrie JE, Berr C, Brunner EJ, Head J, Marmot MG, et al. Alternative healthy eating index and mortality over 18 y of follow-up: results from the Whitehall II cohort. $A m$ $J$ Clin Nutrition 2011;94:247-53.

29 Sabia S, Dugravot A, Kivimaki M, Brunner E, Shipley MJ, Singh-Manoux A. Effect of intensity and type of physical activity on mortality: results from the Whitehall II cohort study. Am J Public Health 2012;102:698-704.

30 World Health Organization. The challenge of obesity in the WHO European Region and the strategies for response. WHO Regional Office for Europe, 2007.

31 Alberti KG, Eckel RH, Grundy SM, Zimmet PZ, Cleeman JI, Donato KA, et al. Harmonizing the metabolic syndrome: a joint interim statement of the International Diabetes Federation Task Force on Epidemiology and Prevention; National Heart, Lung, and Blood Institute; American Heart Association; World Heart Federation; International Atherosclerosis Society; and International Association for the Study of Obesity. Circulation 2009;120:1640-5.

32 Chobanian AV, Bakris GL, Black HR, Cushman WC, Green LA, Izzo JL Jr, et al. Seventh report of the Joint National Committee on Prevention, Detection, Evaluation, and Treatment of High Blood Pressure. Hypertension 2003:42:1206-52.

33 Hardoon SL, Morris RW, Whincup PH, Shipley MJ, Britton AR, Masset G, et al. Rising adiposity curbing decline in the incidence of myocardial infarction: 20-year follow-up of British men and women in the Whitehall II cohort. Eur Heart J 2012;33:478-85.

34 Tabak AG, Jokela M, Akbaraly TN, Brunner EJ, Kivimaki M, Witte DR. Trajectories of glycaemia, insulin sensitivity, and insulin secretion before diagnosis of type 2 diabetes: an analysis from the Whitehall II study. Lancet 2009;373:2215-21.

35 Alberti KG, Zimmet PZ. Definition, diagnosis and classification of diabetes mellitus and its complications. Part 1: diagnosis and classification of diabetes mellitus provisional report of a WHO consultation. Diabet Med 1998;15:539-53.

36 Wooldridge JM. Inverse probability weighted estimation for general missing data problems. $J$ Econometrics 2007;141:1281-301.

37 Everhart JE, Pettitt DJ, Bennett PH, Knowler WC. Duration of obesity increases the incidence of NIDDM. Diabetes 1992:41:235-40.

38 Imkampe AK, Gulliford MC. Increasing socio-economic inequality in type 2 diabetes prevalence-repeated cross-sectional surveys in England 1994-2006. Eur J Public Health 2011;21:484-90.

39 Espelt A, Arriola L, Borrell C, Larranaga I, Sandin M, Escolar-Pujolar A. Socioeconomic position and type 2 diabetes mellitus in Europe 1999-2009: a panorama of inequalities. Curr Diabetes Rev 2011:7:148-58.

40 Lawlor DA, Hart CL, Hole DJ, Davey Smith G. Reverse causality and confounding and the associations of overweight and obesity with mortality. Obesity 2006;14:2294-304.

41 Astrup A, Finer N. Redefining type 2 diabetes: 'diabesity' or 'obesity dependent diabetes mellitus'? Obesity Rev 2000;1:57-9.

42 Prince SA, Adamo KB, Hamel ME, Hardt J, Gorber SC, Tremblay M. A comparison of direct versus self-report measures for assessing physical activity in adults: a systematic review. Int J Behav Nutr Phys Act 2008;5:56. 
43 Samuel-Hodge CD, Fernandez LM, Henriquez-Roldan CF, Johnston LF, Keyserling TC. A comparison of self-reported energy intake with total energy expenditure estimated by accelerometer and basal metabolic rate in African-American women with type 2 diabetes. Diabetes Care 2004;27:663-9.

44 Zins M, Gueguen A, Kivimaki M, Singh-Manoux A, Leclerc A, Vahtera J, et al. Effect of retirement on alcohol consumption: longitudinal evidence from the French Gazel cohort study. PLoS One 2011;6:e26531.

45 Shah S, Cook DG. Inequalities in the treatment and control of hypertension: age, social isolation and lifestyle are more important than economic circumstances. J Hypertension 2001;19:1333-40.

46 National Cholesterol Education Program. Third report of the Expert Panel on Detection, Evaluation, and Treatment of High Blood Cholesterol in Adults. National Institutes of Health, 2002.

47 Narayan KMV, Zhang P, Kanaya AM, Williams DE, Engelgau MM, Imperatore G, et al. Diabetes: the pandemic and potential solutions. In: Jamison DT, Breman JG, Measham AR, Alleyne G, Claeson M, Evans DB, et al, eds. Disease control priorities in developing countries. International Bank for Reconstruction and Development/The World Bank Group, 2006.

48 Tuomilehto J, Lindstrom J, Eriksson JG, Valle TT, Hamalainen H, Ilanne-Parikka P, et al . Prevention of type 2 diabetes mellitus by changes in lifestyle among subjects with impaired glucose tolerance. N Engl J Med 2001;344:1343-50.

49 Wan Q, Wang F, Guan Q, Liu Y, Wang C, Feng L, et al. Regression to normoglycaemia by fenofibrate in pre-diabetic subjects complicated with hypertriglyceridaemia: a prospective randomized controlled trial. Diabet Med 2010;27:1312-7.

50 De Silva NM, Freathy RM, Palmer TM, Donnelly LA, Luan J, Gaunt T, et al. Mendelian randomization studies do not support a role for raised circulating triglyceride levels influencing type 2 diabetes, glucose levels, or insulin resistance. Diabetes 2011;60:1008-18.

51 McGarry JD. Banting lecture 2001: dysregulation of fatty acid metabolism in the etiology of type 2 diabetes. Diabetes 2002;51:7-18.
52 Athyros VG, Tziomalos K, Karagiannis A, Mikhailidis DP. Lipid-lowering agents and new onset diabetes mellitus. Expert Opin Pharmacother 2010;11:1965-70.

53 AIM-HIGH Investigators. Niacin in patients with low HDL cholesterol levels receiving intensive statin therapy. N Engl J Med 2011;365:2255-67.

54 Kivimaki M, Shipley MJ, Ferrie JE, Singh-Manoux A, Batty GD, Chandola T, et al. Best-practice interventions to reduce socioeconomic inequalities of coronary heart disease mortality in UK: a prospective occupational cohort study. Lancet 2008;372:1648-54.

55 Marmot MG, Shipley MJ, Hemingway H, Head J, Brunner EJ. Biological and behavioural explanations of social inequalities in coronary heart disease: the Whitehall II study. Diabetologia 2008;51:1980-8.

56 Carnethon MR, Kinder LS, Fair JM, Stafford RS, Fortmann SP. Symptoms of depression as a risk factor for incident diabetes: findings from the National Health and Nutrition Examination Epidemiologic Follow-up Study, 1971-1992. Am J Epidemiol 2003:158:416-23.

57 Barker DJ. The fetal origins of type 2 diabetes mellitus. Ann Intern Med 1999:130:322-4.

58 Lawlor DA, Ebrahim S, Davey Smith G. Socioeconomic position in childhood and adulthood and insulin resistance: cross sectional survey using data from British women's heart and health study. BMJ 2002;325:805

Accepted: 25 July 2012

\section{Cite this as: BMJ 2012;345:e5452}

This is an open-access article distributed under the terms of the Creative Commons Attribution Non-commercial License, which permits use, distribution, and reproduction in any medium, provided the original work is properly cited, the use is non commercial and is otherwise in compliance with the license. See: $\mathrm{http}: / / c r e a t i v e c o m m o n s . o r g / l i c e n s e s / b y-$ nc/2.0/ and http://creativecommons.org/licenses/by-nc/2.0/legalcode. 


\section{Tables}

Table 1/ Study participants' characteristics at phase 3 (baseline) and incidence of diabetes over 17.7 years of follow-up by socioeconomic status. Values are numbers (percentages) unless stated otherwise

\begin{tabular}{|c|c|c|c|c|c|}
\hline & \multicolumn{3}{|c|}{ Socioeconomic status } & \multirow[b]{2}{*}{$P$ value ${ }^{*}$} & \multirow[b]{2}{*}{ All $(n=7237)$} \\
\hline & High $(n=2831 ; 39.1 \%)$ & Intermediate $(n=3292 ; 45.5 \%)$ & Low $(n=1114 ; 15.4 \%)$ & & \\
\hline Incidence of type 2 diabetes $†$ & $243(5.6)$ & $407(8.9)$ & $169(10.9)$ & $<0.001$ & $818(7.9)$ \\
\hline \multicolumn{6}{|l|}{ Demographics } \\
\hline Mean (SD) age (years) & $49.5(5.8)$ & $48.8(6.0)$ & $51.2(6.0)$ & $<0.001$ & $49.4(6.0)$ \\
\hline Men & $2470(87.3)$ & $2273(69.1)$ & $298(26.8)$ & $<0.001$ & $5041(69.7)$ \\
\hline White ethnic group & $2794(98.7)$ & $2971(90.3)$ & $833(74.8)$ & $<0.001$ & $6598(91.2)$ \\
\hline Family history of type 2 diabetes & $246(8.7)$ & $368(11.2)$ & $172(15.4)$ & $<0.001$ & $786(10.9)$ \\
\hline \multicolumn{6}{|l|}{ Health behaviours $¥$} \\
\hline Smoking & $234(7.4)$ & $485(14.9)$ & $241(22.4)$ & $<0.001$ & $960(13.8)$ \\
\hline Heavy drinking & $573(18.7)$ & $505(14.2)$ & $57(9.8)$ & $<0.001$ & $1135(14.9)$ \\
\hline Unhealthy diet & 809 (24.9) & $1212(35.2)$ & $396(45.4)$ & $<0.001$ & $2417(33.6)$ \\
\hline Physical inactivity & $341(14.4)$ & $612(22.4)$ & $477(30.3)$ & $<0.001$ & $1430(21.2)$ \\
\hline \multicolumn{6}{|l|}{ Other metabolic risk factors $¥$} \\
\hline Obesity & $191(7.9)$ & $295(9.8)$ & $176(11.8)$ & $<0.001$ & $662(9.5)$ \\
\hline High triglycerides ( $\geq 1.7 \mathrm{mmol} / \mathrm{L})$ & $760(23.0)$ & $862(26.9)$ & $284(30.9)$ & $<0.001$ & $1906(26.3)$ \\
\hline Low HDL cholesterol (<1.0/1.2 mmol/L in men/women) & $472(15.1)$ & $629(19.5)$ & $249(24.0)$ & $<0.001$ & $1350(18.9)$ \\
\hline High systolic blood pressure ( $\geq 140 \mathrm{~mm} \mathrm{Hg}$ ) & $217(7.5)$ & $252(7.7)$ & $79(7.9)$ & 0.72 & $548(7.7)$ \\
\hline
\end{tabular}

HDL=high density lipoprotein.

*For linear trend across socioeconomic categories.

†Age, sex, and ethnicity adjusted incidence rate per 1000 person years.

$\ddagger$ Age, sex, and ethnicity adjusted prevalence. 
Table 2| Association of health behaviours and other risk factors assessed at baseline (phase 3 ) with type 2 diabetes incidence ( $\mathrm{n}=\mathbf{7 2 3 7}$ ) Behaviour/risk factor Hazard ratio* $(95 \% \mathrm{Cl})$

Family history of type 2 diabetes (yes $v$ no) $\quad 2.15$ (1.82 to 2.55 )

Smoking (yes $v$ no) $\quad 1.47$ (1.22 to 1.78$)$

Alcohol consumption:

\begin{tabular}{|c|c|}
\hline Abstainers ( 0 units/week) $v$ moderate drinkers $\dagger$ & $1.21(1.02$ to 1.44$)$ \\
\hline Heavy ( $\geq 21 / 14$ units/week for men/women) $v$ moderate drinkers $\dagger$ & $1.04(0.85$ to 1.27$)$ \\
\hline \multicolumn{2}{|l|}{ Diet: } \\
\hline Unhealthy $v$ healthy $\ddagger$ & $1.36(1.15$ to 1.61$)$ \\
\hline Moderately healthy $v$ healthy $\ddagger$ & 0.96 (0.81 to 1.15$)$ \\
\hline \multicolumn{2}{|l|}{ Physical activity: } \\
\hline Inactive $v$ active & $1.33(1.13$ to 1.56$)$ \\
\hline Moderately active $v$ active & $1.25(1.04$ to 1.5$)$ \\
\hline \multicolumn{2}{|l|}{ Body mass index: } \\
\hline Overweight $(25-29 v<25)$ & 1.92 (1.64 to 2.25$)$ \\
\hline Obese $(\geq 30 v<25)$ & 4.79 (3.96 to 5.80$)$ \\
\hline High triglycerides§ (yes $v$ no) & 2.98 (2.59 to 3.42$)$ \\
\hline Low high density lipoprotein cholesterolף (yes $v$ no) & $2.24(1.93$ to 2.59$)$ \\
\hline High systolic blood pressure ${ }^{\star *}$ (yes v no) & $1.86(1.51$ to 2.28$)$ \\
\hline
\end{tabular}

*Adjusted for age, sex, and ethnicity.

†1-21/1-14 units/week for men/women

$\ddagger$ Healthy=upper third of alternative healthy eating index (see Methods).

$\S \geq 1.7 \mathrm{mmol} / \mathrm{L}$.

I $<1.0 / 1.2 \mathrm{mmol} / \mathrm{L}$ in $\mathrm{men} /$ women.

${ }^{* *} \geq 140 \mathrm{~mm} \mathrm{Hg}$. 
Table 3 Contribution of baseline risk factors/markers (phase 3 ) in explaining social inequalities in type 2 diabetes incidence ( $n=7237)$

Baseline risk factors/markers

Hazard ratio $(95 \% \mathrm{Cl}) \quad \%$ difference $^{*}(95 \% \mathrm{Cl})$

Model $1 \dagger$ : lowest $v$ highest socioeconomic status

1.86 (1.48 to 2.32$)$

Model 1 + smoking

1.76 (1.40 to 2.21$)$

$-9(-47$ to 22$)$

Model $1+$ alcohol

1.82 (1.45 to 2.29$)$

$-3(-32$ to 32$)$

Model $1+$ diet

1.76 (1.40 to 2.21$)$

-8 ( -44 to 22$)$

Model $1+$ physical activity

1.85 (1.47 to 2.32$)$

-1 ( -37 to 29$)$

Model 2: model $1+$ all health behaviours

1.67 (1.32 to 2.10$)$

$-17(-58$ to 15$)$

Model $1+$ body mass index

1.66 (1.32 to 2.08$)$

$-18(-57$ to 15$)$

Model 3: model 2 (all health behaviours) + body mass index

1.51 (1.19 to 1.91$)$

$-33(-78$ to 1$)$

Model $3+$ triglycerides

1.40 (1.11 to 1.77$)$

$-13 \ddagger(-35$ to 5$)$

Model $3+$ high density lipoprotein cholesterol

1.46 (1.16 to 1.85$)$

$-5 \ddagger(-12$ to 1$)$

Model $3+$ systolic blood pressure

1.50 (1.19 to 1.91$)$

$-1 \neq(-15$ to 8$)$

Model 4: all above risk factors

1.40 (1.11 to 1.78$)$

$-45(-105$ to -17$)$

*Percentage attenuation in log $\mathrm{HR}=100 \times\left(\beta_{\mathrm{SES}}-\beta_{\mathrm{SES}+\text { risk factor(s) }}\right) /\left(\beta_{\mathrm{SES}}\right)$, where $\beta=\log (\mathrm{HR})$.

†Adjusted for age, sex, ethnicity, and family history of type 2 diabetes.

¥Additional contribution of risk factor to model adjusted for all health behaviours and body mass index (model 3). 
Table 4 | Contribution of repeatedly measured risk factors/markers in explaining social inequalities in type 2 diabetes incidence ( $\mathbf{n}=\mathbf{7 2 3 7})$

\begin{tabular}{|c|c|c|c|c|}
\hline \multirow[b]{2}{*}{ Model } & \multicolumn{2}{|c|}{ Longitudinal assessment ${ }^{*}$} & \multicolumn{2}{|c|}{ Longitudinal + long term assessment $†$} \\
\hline & Hazard ratio $(95 \% \mathrm{Cl})$ & $\%$ difference $¥(95 \% \mathrm{Cl})$ & Hazard ratio $(95 \% \mathrm{Cl})$ & $\%$ difference $\neq(95 \% \mathrm{Cl})$ \\
\hline Model 1§: lowest $v$ highest SES & 1.86 (1.48 to 2.32$)$ & & 1.86 (1.48 to 2.32$)$ & \\
\hline Model $1+$ smoking & 1.80 (1.44 to 2.26$)$ & $-4(-12$ to 1$)$ & 1.78 (1.42 to 2.23$)$ & $-7(-16$ to -2$)$ \\
\hline Model $1+$ alcohol & 1.84 (1.47 to 2.32$)$ & $-1(-9$ to 6$)$ & $1.80(1.43$ to 2.26$)$ & $-5(-14$ to 2$)$ \\
\hline Model $1+$ diet & 1.77 (1.41 to 2.22$)$ & $-8(-15$ to -3$)$ & $1.76(1.40$ to 2.21$)$ & $-8(-16$ to 3$)$ \\
\hline Model $1+$ physical activity & 1.79 (1.43 to 2.24$)$ & $-6(-12$ to -2$)$ & 1.74 (1.39 to 2.19$)$ & $-10(-19$ to -4$)$ \\
\hline $\begin{array}{l}\text { Model 2: model } 1+\text { all health } \\
\text { behaviours }\end{array}$ & $1.69(1.34$ to 2.13$)$ & $-15(-29$ to -5$)$ & 1.60 (1.26 to 2.02$)$ & $-24(-43$ to -11$)$ \\
\hline Model $1+$ body mass index & $1.62(1.29$ to 2.04$)$ & $-22(-39$ to -13$)$ & 1.61 (1.28 to 2.02$)$ & $-23(-41$ to -13$)$ \\
\hline $\begin{array}{l}\text { Model 3: model } 2 \text { (all health } \\
\text { behaviours) + body mass index }\end{array}$ & $1.48(1.17$ to 1.88$)$ & $-36(-64$ to -22$)$ & 1.41 (1.11 to 1.78$)$ & $-45(-75$ to -28$)$ \\
\hline Model $3+$ triglycerides & $1.43(1.13$ to 1.81$)$ & $-6 \boldsymbol{( 1 3}(-13$ to 2$)$ & $1.35(1.06$ to 1.71$)$ & -7 I $(-11$ to 0$)$ \\
\hline Model $3+$ HDL cholesterol & $1.43(1.13$ to 1.81$)$ & -5 I $(-12$ to 2$)$ & $1.37(1.07$ to 1.75$)$ & $-4 \boldsymbol{\uparrow}(-8$ to 2$)$ \\
\hline $\begin{array}{l}\text { Model } 3+\text { systolic blood } \\
\text { pressure }\end{array}$ & $1.49(1.18$ to 1.89$)$ & $19(-1$ to 2$)$ & $1.42(1.12$ to 1.8$)$ & 2 I $(-1$ to 3$)$ \\
\hline Model 4: all above risk factors & $1.41(1.11$ to 1.78$)$ & $-45(-77$ to -28$)$ & 1.35 (1.05 to 1.72$)$ & $-53(-88$ to -29$)$ \\
\hline
\end{tabular}

HDL=high density lipoprotein; SES=socioeconomic status.

${ }^{*}$ Adjustment for risk factors assessed at phases 3,5 , and 7 .

†Risk factors updated at phases 3,5 , and 7 and additionally adjusted for risk factor at previous phase; cumulative exposure to high triglycerides not assessed for time period between phases 1 and 3 , owing to lack of data at phase 1.

¥Percentage attenuation in $\log H R=100 \times\left(\beta_{\text {SES }}-\beta_{\text {sEStrisk tactors }}\right) /\left(\beta_{\text {SES }}\right)$, where $\beta=\log (H R)$.

$\S$ Adjusted for age, sex, ethnicity, and family history of type 2 diabetes

ๆAdditional contribution of risk factor to model adjusted for all health behaviours and body mass index (model 3). 